\title{
PERLUASAN AREAL PEMASARAN MINUMAN INSTAN VITEPLUS PRODUKSI UD MAJU JAYA SUMENEP
}

\author{
Ismawati $^{1}$, Aryo Wibisono ${ }^{2}$, Ratih Yuniastri ${ }^{1}$ \\ ${ }^{1}$ Program Studi Teknologi Hasil Pertanian, Fakultas Pertanian \\ ${ }^{2}$ Program Studi Manajemen, Fakultas Ekonomi \\ Universitas Wiraraja \\ Email: ismawati@wiraraja.ac.id
}

\begin{abstract}
Partners in PKM activities is UD Maju Jaya with the product soursop leaf instans drink called viteplus. Viteplus is a instan drink from powder product made from sugar which is formulated with soursop leaf exstract and traditional herbal ingredients. In running a business, partners have been able to increase production capacity. Increasing production capacity also needs to be supported by increased marketing so that businesses can continue to run and be profitable. Through PKM activities, the team provides assistance to partners in solving problems faced, namely increasing marketing. Marketing increase is measured based on the product marketing area. Activities carried out as an effort to provide solutions to partners, namely training, mentoring and monitoring. The results of PKM activities indicate an increase in the product marketing area of $>50 \%$, where before the activity the product was only marketed in 3 districts and after PKM activities increased the marketing area to 5 districts, namely Gapura, Sumenep City District, Bluto, Ganding and Guluk - Guluk.
\end{abstract}

Keywords: market area, instant drink, expantion

\begin{abstract}
Abstrak. Mitra dalam kegiatan PKM adalah UD Maju Jaya denga n produk minuman instan daun sirsak dengan nama produk viteplus. Viteplus merupakan produk yang minuman dalam bentuk bubuk yang terbuat dari gula pasir yang diformulasi dengan sari daun sirsak dan bahan jamu tradisional. Dalam menjalankan usaha, mitra telah mampu mennigkatkan kapasitas produksi. Peningkatan kapasitas produksi perlu didukung juga oleh peningkatan pemasaran agar usaha dapat terus berjalan dan profitable. Melalui kegiatan PKM tim melakukan pendampingan terhadap mitra dalam menyelesaikan permsalahan yang dihadapi yaitu peningkatan pemasaran. Peningkatan peasaran diukur berdasarkan areal pemasaran produk. Kegiatan yang dilakukan sebagai upaya memberikan solusi terhadap mitra yaitu pelatihan, pendampingan dan monitoring. Hasil kegiatan PKM menunjukkan adanya peningkatan areal pemasaran produk $>50 \%$, dimana sebelum kegiatan produk hanya dipasarkan di 3 kecamatan dan setelah kegiatan PKM meningkat areal pemasarannya menjadi 5 kecamatan antara lain Gapura, Kecamatan Kota Sumenep, Bluto, Ganding dan Guluk - Guluk.
\end{abstract}

Kata kunci : areal pemasaran, minuman instan, perluasan

\section{PENDAHULUAN}

Produk viteplus berupa minuman instan dalam bentuk bubuk dengan bahan utama berupa gula pasir yang diformulasikan dengan sari daun sirsak dan bahan jamu tradisional lainnya. Munculnya produk viteplus berdasar atas tren konsumsi masyarakat saat ini yang mulai mengarah pada makanan dan minuman yang berkasiat bagi kesehatan yang memberikan peranan sebagai obat/pencegahan atau untuk penyegar. Tren konsumsi masyarakat saat ini lebih memperhatikan waktu penyiapan yang efektif, pangan sehat yaitu makanan yang tidak merugikan kesehatan dan pangan fungsional yaitu makanan yang dapat mendukung kekebalan tubuh, metabolisme dan mampu mencegah penyakit (Sucipta, Suriasih, \& Kenacana, 2017).
Pemasaran merupakan suatu aspek yang sangat penting bagi UMKM sebagai usaha produktif ekonomi. Termasuk dalam hal ini UD Maju Jaya sebagai mitra yang memproduksi minuman instan daun sirsak dengan nama produk viteplus juga mengalami permasalahan dalam pemasaran. Permasalahan pemasaran antara lain masih terbatasnya lokasi pemasaran yang yaitu di 3 kecamatan yang ada di Kabupaten Sumenep. Meskipun produk viteplus telah ada sejak tahun 2017 dan juga telah memiliki label halal dari LPPOM MUI namun keunggulan ini masih belum didukung dengan perluasan pemasaran karena terbatasnya pemahaman mitra dalam memasarkan produk. Perkembangan lain yang juga dapat dilihat pada usaha mitra yaitu cara produksi yang sebelumnya dilakukan dengan cara 
manual saat ini telah mulai menerapkan teknologi pada proses pembuatan bubuk dan proses pengemasan. Sebagai contoh dimana pada proses pembuatan bubuk dilakukan dengan ditumbuk menggunakan lumpang dan alu namun saat ini telah menggunakan mesin penepung disk mill (Ismawati, Wibisono, \& Yuniastri, 2020). Adopsi teknologi dan penggunaan peralatan tentu berdampak pada peningkatan kepasitas produksi. Peningkatan kapasitas produksi ini yang akhirnya perlu diimbangi dengan perluasan areal pemasaran dimana pemasaran produk UMKM lokal secara umum masih dinilai kurang (Gunartin, 2017). Meskipun mitra telah mengembangkan proses produksi dengan penggunaan peralatan yang semi otomatis pada produksi dan pengemasan, namun upaya perluasan area pemasaran belum dilakukan karena pemahaman terkait pemasaran masih kurang.

Dalam perluasan pemasaran terdapat faktor penting yang juga berdampak pada keberlanjutan yaitu kontinouitas ketersediaan produk. Ketersediaan produk sendiri sangat berkaitan dengan ketersediaan bahan baku disamping faktor kemampuan/kapasitas produksi (Ariani \& Utomo, 2017). Berdasarkan aspek bahan baku sudah dapat dipastikan bahwa di wilayah mitra banyak tersedia bahan baku berupa daun sirsak dan rempah sebagai bahan tambahan. Ketersediaan bahan baku dan kemampuan produksi mitra saat ini menjadikan pentingnya dilakukan perluasan areal pemasaran agar usaha mitra dapat berjalan secara kontinu serta dapat lebih berkembang dibandingkan sebelum adaya peningkatan kapasitas produksi. Pendampingan mitra dalam perluasan areal pemasaran merupakan upaya yang diharapkan dapat mendukung perkembangan usaha mitra dimana sampai saat ini di Indonesia sendiri UMKM masih menjadi salah satu penguat perkembangan ekonomi dengan penyerapan tenaga kerja yang cukup tinggi (Hafni \& Rozali, 2017).

Berdasar pada permasalahan mitra maka tim memberikan pelatihan pemasaran pada mitra serta memberikan pendampingan dalam proses perluasan pemasaran. Pelatihan pemasaran yang diberikan meliputi pelatihan promosi sebagai upaya untuk memperkenalkan produk dan merangsang keinginan pembelian dari calon konsumen. Pendampingan pemasaran pada usaha mitra dilakukan dengan cara mendampingi proses promosi pada usaha mitra. Upaya pelatihan maupun pendampingan ditujukan untuk peningkatan pemasaran produk yang ditinjau berdasarkan areal atau wilayah pemasaran. Areal pemasaran sebelum kegiatan yaitu di 2 kecamatan antara lain Gapura dan Guluk - Guluk melalui upaya yang dilakuakn oleh tim PKM dan mitra maka nantinya akan dapat ditingkatkan areal pemasarannya. Semakin luas areal pemasaran produk maka akan semakin banyak pula yang akan melihat dan mengenal produk viteplus. Tulisan ini merupakan bentuk informasi dari hasil kegiatan PKM (pengabidan kepada masyarakat) dengan harapan dapat dijadikan referensi atau bahan acuan oleh pelaksana kegiatan selanjutnya dengan kajian topik yang sama.

\section{METODE PELAKSANAAN}

Kegiatan PKM dilaksanakan dengan 3 tahap utama yaitu pelatihan, pendampingan dan monitoring. Teknis dalam pelaksanaan 3 tahapan dalam kegiatan PKM sebagaimana berikut:

1. Pelatihan Pemasaran

Kegiatan pelatihan pemasaran dilakukan langsung oleh anggota tim PKM di lokasi mitra. Peserta pelatihan adalah pemilik dan satu orang bagiaan produksi. Pelatihan dilaksanakan pada bulan Juli 2020 dimana bertepatan dengan terjadinya pandemi covid 19, sehingga peserta pelatihan dibatasi. Kegiatan pelatihan dilakukan dengan mematuhi protokol kesehatan.

2. Pendampingan

Pendampingan dilakukan sebagaii follow up dari kegiatan pelatihan pemasaran yang telah dilakukan. Pendampinga dilakukan secara langsung dengan cara bertemu langsung antara tim PKM dan mitra dan pendampingan tidak langsung yaitu pendampingan secara daring via telepon dan whattsap. Pendampingan pemasaran lebih diutamakan pada promosi secara langsung maupun daring. Promosi daring dilakukan pada media 
online antara lain facebook, instagram dan youtube. Kegiatan pendampingan setelah proses pelatihan terbukti memberikan dampak positif terhadap mitra binaan dalam mempraktikkan hasil yang didapatkan dari kegiatan pelatihan (Ismawati, Destryana, \& Wibisono, 2019).

3. Monitoring

Monitoring dilakukan oleh tim PKM terhadap mitra dan kegiatan mitra setelah proses pelatihan dan pendampingan. Monitoring juga bertujuan untuk mengevaluasi dan merencanakan tindak lanjut atas hasil monitoring yang telah dilakukan. Evaluasi terbukti dapat meningkatkan peran serta anggota tim dalam menerapkan hasil pelatihan yang diperoleh (Mulyono \& Roniardian, 2018). Monitoring yang dilakukan oleh tim PKM yaitu berupa peninjaun langsung terhadap jalannya usaha mitra dan peninjauan produk yang dipasarkan ke beberapa lokasi pemasaran. Monitoring yang dilakukan juga merupakan pengukuran capaian tujuan oleh tim PKM secara langsung atau survei.

\section{HASIL DAN PEMBAHASAN Pelaksanaan Kegiatan}

Ketercapaian luaran dan manfaat kegiatan dapat diperoleh dalam pelaksanaan PKM atas kerjasama yang baik antara tim PKM dan tim mitra. Pelaksanaan kegiatan pelatihan diikuti dengan seksama oleh mitra. Pelatihan yang diberikan pada mitra berupa pelatihan langsung khusus pada untuk mensosialisasikan produk viteplus kepada masyarakat luas. Tim PKM yang memiliki kualifikasi dalam bidang manajemen pemasaran memberikan pelatihan terkait promosi pada media sosial yaitu facebook, instagram dan youtube. Upaya lain yang juga dilakukan oleh tim PKM dalam mendukung kegiatan promosi produk yaitu mitra dibuatkan akun media sosial. Dalam rangka mensosialisasikan produk untuk membangun brand dilakukan pendampingan. Pendampingan merupakan bentuk follow up yang dinilai dapat efektif memberikan dampak positif terhadap pencapaian tujuan kegiatan pelatihan (Zahidi, Prakoso, \& Agustino, 2020). Berdasarkan pada hasil monitoring mitra juga aktif menggunakan fasilitas media sosial dalam mengenalkan produk kepada masyarakat luas.

Pelaksanaan kegiatan pelatihan pemasaran khususnya dalam hal promosi online memberikan hasil bahwa mitra telah melaksanakan upaya promosi sesuai dengan hasil kegiatan pelatihan. Implementasi hasil pelatihan oleh mitra membuktikan bahwa mitra memang selalu antusias dalam mengikuti kegiatan pelatihan dengan baik. Tercapainya hasil sesuai keinginan bersama merupakan bukti adanya bekerjasama yang baik meskipun sedikit terkendala akibat terjadinya pandemi covid 19. Dokumentasi kegiatan PKM sebagaimana pada Gambar 1.

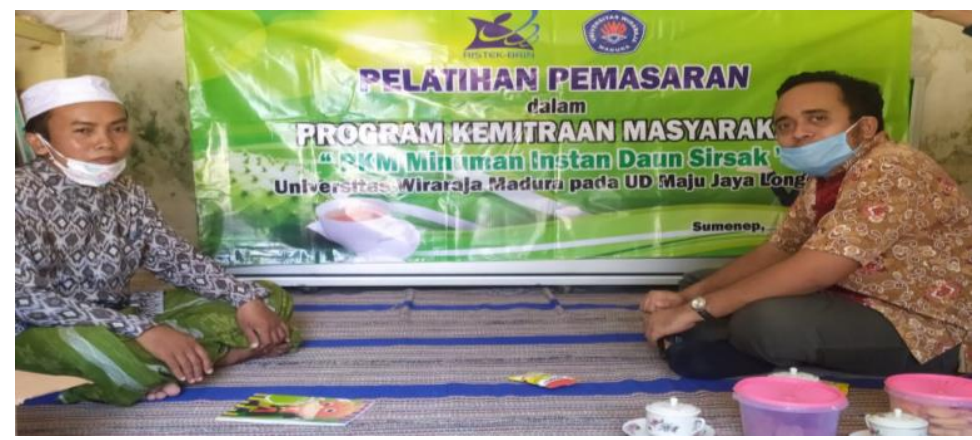

Gambar 1. Pelatihan Pemasaran oleh Tim PKM 
Hasil kegiatan pemberdayaan melalui selama kegiatan PKM sebagaimana disajikan Iptek yang ditranspormasikan kepada mitra pada Tabel 1.

Tabel 1. Hasil kegiatan

\begin{tabular}{lllll}
\hline No & Aspek yang Diukur & Sebelum & Sesudah & Keterangan \\
\hline 1 & Pemahaman pemasaran & Kurang & Meningkat & $\begin{array}{l}\text { Diukur berdasarkan } \\
\text { kemampuan mitra } \\
\text { menyusun media promosi } \\
\text { online setelah pelatihan }\end{array}$ \\
\hline 2 & Instrumen promosi & Belum ada & Sudah ada & $\begin{array}{l}\text { Media promosi di outube, } \\
\text { facebook dan IG }\end{array}$ \\
\hline 3 & Areal pemasaran & 2 kecamatan & 5 Kecamatan & $\begin{array}{l}\text { Mengalami peningkatan } \\
\text { jumlah areal pemasaran di } \\
\end{array}$ \\
& & & 3 kecamatan. \\
\hline
\end{tabular}

\section{Terciptanya Media Promosi}

Tercapainya peningkatan area pemasaran produk serta dukungan sarana produksi yang cukup pada usaha mitra, akhirnya mitra mitra perlu merekrur tenaga kerja baru khususnya bagian pemasaran. Perekrutan tenaga pemasaran sebagaimana yang telah diposting mitra pada bulan Juli 2020 dalam akun media sosial berupa facebook dan instagram produk yang telah dibuatkan oleh tim PKM sebagai salah satu media promosi. Perekrutan tenaga penjual (sales) sampai saat ini belum dapat terpenuhi hal itu dimungkinkan karena pekerjaan sebagai sales termasuk pekerjaan yang beresiko ditengah kondisi pandemi covid 19 . Jumlah pemasaran produk saat ini belum dapat diukur karena pandemi covid-19 sangat mempengaruhi penjualan.
Melalui kegiatan PKM telah dibuat akun video promosi di youtube sebagi upaya mensosialisasikan produk terhadap masyarakat luas. Adapun video yang diunggah sebagi upaya promosi berupa video testimoni dan video proses produksi minuman instan daun sirsak dengan nama produk viteplus. Disamping promosi secara daring juga dilakukan promosi langsung dengan mendesain spanduk produk dan pamlet produk. Spanduk produk disebarkan di 3 antara lain Kecamatan Ganding, Gapura dan Kecamatan Sumenep. menyebarkan pamlet produk ke lokasi pemasaran produk. Desain pamflet produk sebagaimana disajikan pada Gambar 2.

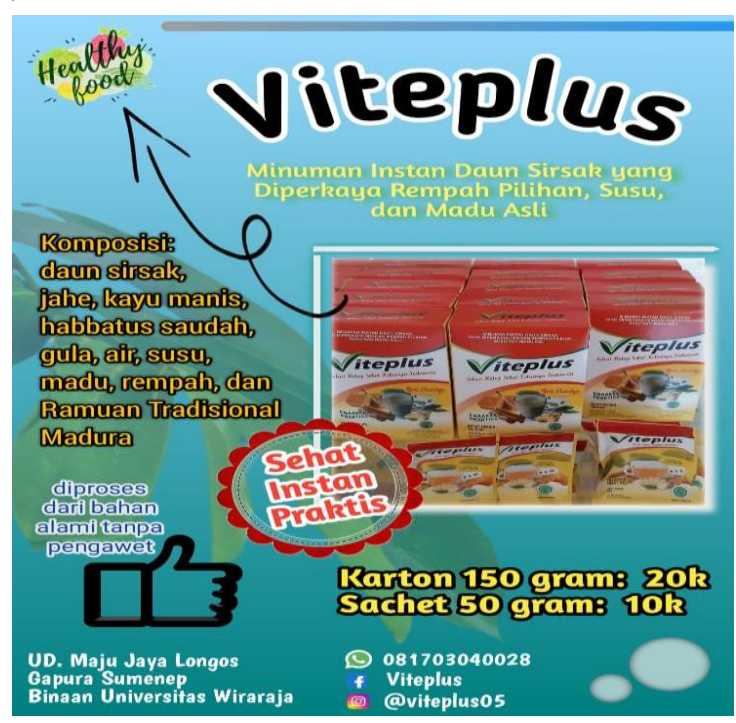

Gambar 2. Pamflet Produk 


\section{Perluasan Areal Pemasaran Produk}

Keberhasilan program diukur

berdasarkan capaian tujuan dari kegiatan yang telah ditetapkan sebelumnya. Dalam pelaksanaan PKM pengukuran capaian tujuan berupa peningkatan areal pemasaran diukur berdasarkan hasil survei langsung tim terhadp usaha mitra sekaligus merupakan kegiatan monitoring oleh tim PKM. Penilaian keberhasilan kegiatan dalam PKM ini adalah adanya peningkatan areal pemasaran dimana jika mitra dapat meningkatkan areal pemasaran sebesar $50 \%$ dari sebelumnya maka rangkaian kegiatan yang dilakukan dapat dikatakan telah berhasil mencapai tujuan kemanfaatan bagi usaha mitra. Pengukuran keberhasilan bukan merupakan terlaksananya kegiatan PKM dengan baik namun output dari tahapan kegiatan. Keberhasilan dalam mendampingi UMKM yang produktif ekonomi adalah kemampuan berproduksi dan kemampuan memasarkan produk yang dihasilkan (Kartawan, Rinandiyana, \& Kurniawan, 2016).

Kemanfaatan yang diperoleh mitra melalui pelatihan dan pendampingan pemasaran yaitu peningkatan jumlah areal pemasaran yang semula hanya dipasarkan di 2 kecamatan meningkatkan menjadi 5 sebelumnya hanya di 2 kecamatan yaitu Kecamatan Gapura dan Kecamatan Guluk Guluk setelah kegiatan PKM menjadi wilayah kecamatan yaitu Gapura, Kecamatan Sumenep, Guluk - Guluk, Ganding dan Bluto. Dokumentasi produk yang ada di minimarket sebagaimana pada Gambar 3 .

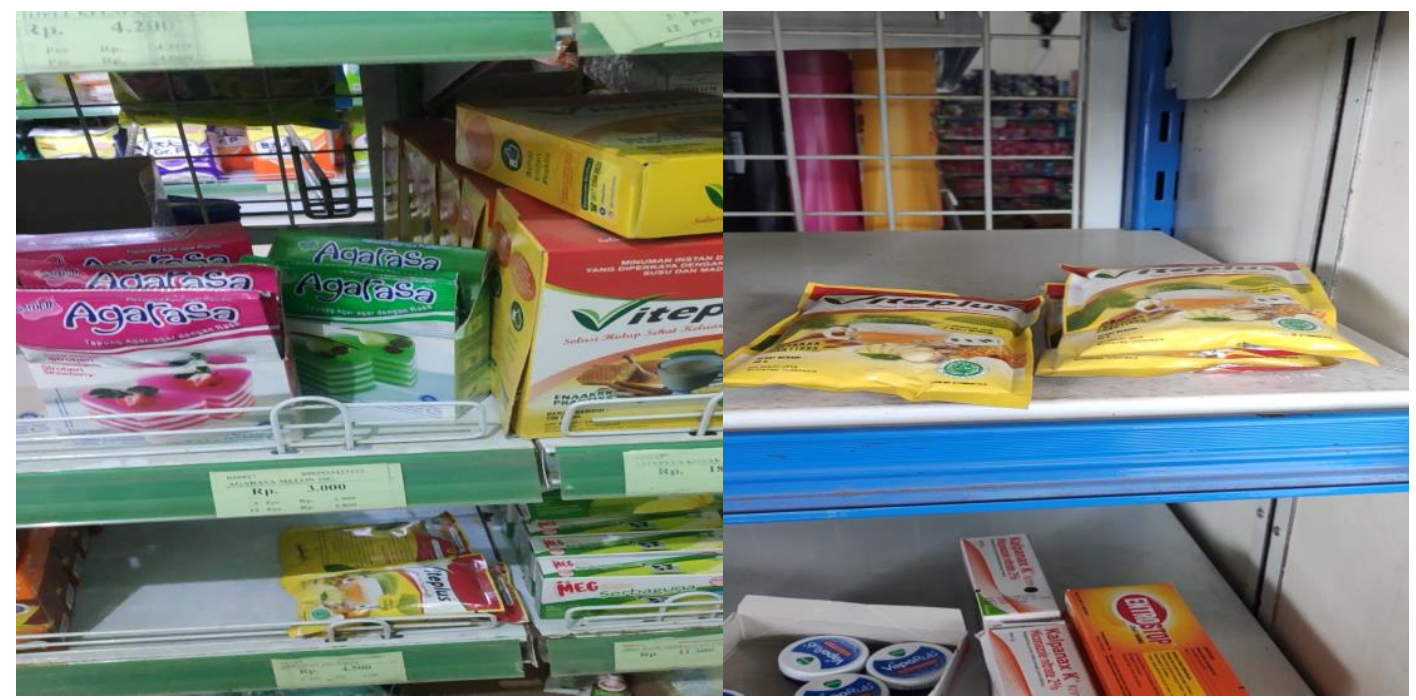

Gambar 3. Dokumentasi produk di mini market

Berdasar pada terciptanya media promosi dan terjadinya perluasan areal pemasaran maka kegiatan pelatihan dan pendampingan yang dilakukan oleh tim PKM telah memberikan kemanfaatan dalam memberikan pemahaman pemasaran khususnya dalam melakukan promosi. Disamping itu dari peningkatan pemahaman pemasaran pada mitra dan terciptanya media promosi juga memberikan dampak terhadap peningkatan areal pemasaran produk viteplus.

\section{SIMPULAN DAN SARAN}

Perluasan areal pemasaran produk mitra (viteplus) dapat tercapai yaitu terjadi penambahan areal pemasaran baru yaitu Kecamatan Ganding dan Kecamatan Bluto sehingga areal pemasaran yang awalnya hanya 3 setelah kegiatan meningkatkan menjadi 5 kecamatan. Pencapaian perluasan areal pemasaran dilakukan dengan tiga tahap kegiatan yaitu pelatihan pemasaran terhadap mitra, pendampingan pemasaran dan monitoring.

Untuk meningkatkan pemasaran yang lebih luas pada usaha minuman instan viteplus 
maka perlu peningkatan mutu produk berupa legalisasi BPOM sebagi jaminan mutu produk bagi konsumen. Untuk mendukung proses pemasaran, mitra juga perlu menambah tenaga pemasaran sebagai sales.

\section{UCAPAN TERIMAKASIH}

Ucapan terimakasih disampaikan kepada tim mitra sebagai objek dalam pelaksanaan Program Kemitraan Masyarakat. Ucapan terimakasih juga disampaikan kepada Kemenristek/BRIN yang memberikan pendanaan hibah pada tahun 2020 .

\section{DAFTAR PUSTAKA}

Ariani, \& Utomo, M. N. (2017). Kajian strategi pengembangan usaha mikro kecil dan menengah (umkm) di kota tarakan. Organisasi Dan Manajemen, 13(2), 99118.

Gunartin. (2017). Penguatan Umkm Sebagai Pilar Membangun Ekonomi Bangsa. Jurnal Pendidikan, Hukum, Dan Bisnis, 2(2), 1-10. https://doi.org/10.1017/CBO978110741532 4.004

Hafni, R., \& Rozali, A. (2017). Analisis Usaha Mikro, Kecil, dan Menengah (umkm) terhadap Penyerapan Tenaga Kerja di Indonesia. Ilmu Ekonomi Dan Studi Pembangunan, 15(2), 77-96. Retrieved from

http://jurnal.umsu.ac.id/index.php/ekawan/a rticle/view/1034/pdf_58

Ismawati, I., Destryana, R. A., \& Wibisono, A. (2019). PELATIHAN TEKNOLOGI PENGEMASAN TABLET EFFERVESCENT, (September), 289-298.

Ismawati, Wibisono, A., \& Yuniastri, R. (2020).
Seminar Nasional Karya Pengabdian Penerapan Teknologi Dalam Peningkatan Kapasitas Produksi UMKM UD Maju Jaya Sumenep. In Seminar Nasional Karya Pengabdian Fakultas Pertanian Universitas Muhammadiyah Mataram (pp. 1-7).

Kartawan, K., Rinandiyana, L., \& Kurniawan, D. (2016). Pengembangan Usaha Melalui Peningkatan Kemampuan Bersaing Produk Umkm Dalam Memasuki Masyarakat Ekonomi Asean. Jurnal Ilmiah Ekonomi Bisnis, 2l(2), 178694. https://doi.org/10.35760/eb.

Mulyono, D. C., \& Roniardian, Y. (2018). Penguatan Peran Warga Masyarakat dalam Perencanaan, Penganggaran, dan Evaluasi Hasil Pembangunan Desa. Jurnal Pengabdian Kepada Masyarakat Indonesion Nournal of Community Engangement, 4(1), 109-118.

Sucipta, I. N., Suriasih, K., \& Kenacana, P. K. . (2017). Pengemasan, Kajian Aman, Yang Efisien, Efektif D A $N$ Efesien. Udayana University Press. Retrieved from http://penerbit.unud.ac.id

Zahidi, M. S., Prakoso, H. A., \& Agustino, H. (2020). Pendampingan Petani Muda Kopi Robusta Dalam Upaya Meningkatkan Eksistensi Petani Kopi Di Desa Amadanom, Kecamatan Dampit .... Jurnal Terapan ..., 125-133. Retrieved from http://ejournal.unipma.ac.id/index.php/JTA/article/ view/5174 